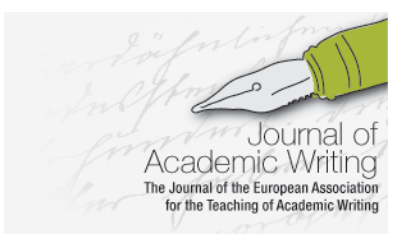

Journal of Academic Writing Vol. 8 No 2 Winter 2018, pages 114-123 http://dx.doi.org/10.18552/joaw.v8i2.466

\title{
Coming around: Tutors, Orientation, and Prolepsis
}

\author{
Deryn P. Verity \\ The Pennsylvania State University, USA
}

\begin{abstract}
Novice tutors often conceptualize learning how to tutor as a kind of metaphorical journey, one with a compelling, but not fully recognized, destination. Cognitively speaking, they are learning how to tutor while at the same time learning what the activity of tutoring means. This paper seeks to position tutor education within the conceptually rich field of teacher education, especially as it is informed by insights from sociocultural theory (SCT). Using tutors' reflective narratives, the author illuminates how orientation to task, a fundamental concept in SCT, changes over time through frequent and intensive reflective writing, when carried out in combination with practical tutoring activities. Specifically, the data suggests that proleptic engagement (identifying elements of the future expert self in ongoing novice activity) and affective engagement are important signals of development. The journey is particularly challenging because - to interrogate the metaphor - the novice is trying to build the track while riding the train to the terminus.
\end{abstract}

\section{Introduction: Reflective Narratives in Teacher Education}

First-year students in the MATESL program at our large state university are required to take a semester-long tutoring internship as one of their two 'field experience' classes (the other is a teaching practicum in the second year). The data discussed in this paper is excerpted from the set of reflective narratives written by these tutoring interns. *

The tutees (who earn one academic credit) are volunteers from a multi-section writing program for matriculated international undergraduates taking the class to fulfill a first-year writing requirement. Tutors meet their tutees individually once a week for about 40 minutes for 12 or 13 sessions (in a 15-week semester), for a total of approximately 7-9 hours of one-on-one tutoring. Because most of our MATESL students are themselves second-language writers and speakers of English who arrive in our program straight from their own undergraduate work, they tend to bring scant instructional experience to the internship.

Drawing upon the philosophy of the department which houses the MATESL program, namely sociocultural theory grounded in the work of Vygotsky (Lantolf and Poehner 2008, Lantolf and Poehner 2014), the tutoring internship is designed to be an arena of praxis. That is, it engages the novice tutors in concrete practice directly informed by, and intertwined with, theoretical instruction. To this end, in addition to tutoring, interns gather weekly with the class supervisor for discussions of theoretical readings, practical workshops and trouble shooting. To document their tutoring activity, the tutors are required to write and post a reflective comment (c350-500 words) within 48 hours of every tutoring session they hold. These comments are published on a 'discussion board' on the electronic classroom management system, visible only to members of the class. Interns are generally encouraged to read and respond to each other's posts, though the supervisor is the only person who reads and responds to every single post.

Supervisor feedback focuses on providing moral support and reminding tutors of basic principles from class discussions. If a tutor asks a direct question or reports a difficulty, the 
supervisor may offer a helpful suggestion, but the goal of the discussion board dialogue is to support and maintain a sense of focus and motivation rather than to provide a help desk. (Indeed, a common response to a question is to encourage the tutor to contact the classroom instructor for clarification. Tutors are asked to visit their tutees' classrooms at least once during the semester.) No scores or grades are assigned to individual posts, though $50 \%$ of the final grade is awarded for a punctual and complete record of reflective posts.

The course culminates in an 8-10 page final paper (submitted online, visible only to the supervisor), which takes the form of a longer reflective narrative. In these final narratives, tutors are asked to draw upon the posts they have written, and on class readings and discussions, to analyze and reflect upon their own development. Interns are encouraged to characterize their experience through an analogy, and they often select the analogy of a 'journey' to describe their growth as tutors, which is not surprising. When gaining expertise, there is a sense of forward momentum, and of changing internal and external landscapes, illustrated by the following excerpts from final course papers:

This is my journey to a better tutor. It's hard to say what the best tutor is. Maybe there isn't such a stage, since we can always make progress and become better and better.

this balance was something I had to learn and become accustomed to as a novice tutor.

not only does it involve breaking down the inner workings of the writing process, but it more importantly involves establishing a positive relationship with a tutee.

Teacher educators see writing reflective narratives as a powerful technique for helping novice teachers make sense of their experience (Daniels 2013, Golombek and Johnson 2004, Johnson and Golombek 2016). Reflective teacher narratives tend to highlight the unpredictable nature of development, the fact that the journey from novice to expert is rarely linear. As lenses on experience, narratives are both retrospective (looking backwards at past events) and retrodictive (explaining what those events mean) (Polkinghorne 1988). From the viewpoint of SCT (Lantolf and Poehner 2008, Lantolf and Poehner 2014), narratives underscore the importance of the 'genetic heuristic' for understanding proficiency. That is, performance itself is opaque: we cannot understand today's performance without knowing the full story of yesterday.

And tomorrow? This paper suggests that one benefit of reflection is that it is double-edged: it recounts a backward looking story of genesis (what happened to me, how and why?) and at the same time suggests a forward-looking story of exodus (where am I going to be later, after I leave this stage of development?). In SCT terms, the act of reflection can be a psychological tool, a meaning-infused set of symbolic actions, used by the teacher/writer to create what Vygotsky calls a ZPD, a zone of future development (John-Steiner and Mahn 1996).

\section{Objective Knowledge vs. Intersubjectivity}

A basic principle of SCT is that education ideally results not in accumulation: what does the tutor know? how much knowledge, how many rules? [...] but in transformation: how does the tutor know? Instruction is not primarily about giving students information; it is an act of engagement with another person for the purpose of helping that person transform the quality of their activity (in this case, the mastery of academic writing in a second language). As one tutoring intern comments after a mid-semester session with a tutee:

I find myself continuing to learn as I go. As I dig for material and resources to help my tutees, and as I explain things to my tutees I get better grasp of them, i.e. the more I teach any subject the better I get good command of it.

Thus, a tutor must develop a range of knowledge, one that covers not only objective facts and concepts about academic writing but also strategic knowledge of how to use those facts and 
concepts to build intersubjectivity with the tutee regarding the goals and actions of the tutoring relationship (Sengupta and Xiao 2002).

A tutor writes after the first tutoring session:

I am not a writing expert, thus I think I need to read some academic writing books for reference as well. I'm sure we can learn from each other and improve our English writing ability together.

And, after the second, displays an intuitive understanding that being a good tutor is not limited to knowing a lot about writing:

it is hard to ask and I feel struggling when tutees keep long-time silent after being asked. I hope I can gain more asking skills because they are extremely important in tutoring session.

'Asking skills' is this novice's vocabulary for pedagogical responsiveness to the tutee's perceived level of understanding. In SCT terms, this tutor is coming to see the importance of intersubjectivity, a set of (possibly temporary) mutually constructed meanings created in collaboration with the learner (Linell 2003). Intersubjective meanings arise from the specific, personal and unpredictable ways in which the tutor, tutee and tutee's written texts interact with established meanings. Successful instruction of any kind proceeds because of a perhaps tacit, but always mutually established, understanding between participants in dialogue with each other. Many of our tutoring interns are executing the role of instructor for the first time; it takes some weeks for them to realize that tutoring is not about fixing paragraphs, but about helping people learn how to write. Learning to be a good tutor means learning how to think, speak, and act in ways that mediate that learning in their tutees.

Around the mid-point of the semester, one tutor makes an oblique reference to a mutually constructed 'method' that she and her tutee have developed to help the tutee create unified paragraphs. The tutor's comment illustrates that intersubjectivity was created, which expanded the power of her mediating activity:

At that point, Tutee $\mathrm{K}$ seemed confident that she could use the method herself on other sections, which was a particularly exciting thing for me - I was really developing her as a writer, and not just helping with her essay!

Naturally, novice tutors do not know much about the role of strategic mediation at first; indeed, when they enter the internship, their orientation towards the activity of tutoring foregrounds the importance of established knowledge and static relationships, as these early-semester posts show:

an instructor or a tutor, he or she is supposed to play the role as a knowledge conveyer.

I don't feel I have the ability to improve her grammar. I am not sure what I can do here.

When I had some discussions with other tutors, our biggest concern was all about whether we were qualified to be a writing tutor: 'We are not native speakers. We didn't get good grades in TOFEL or GRE writing session. How can we teach others?'.

Of course, the role of objective knowledge in good instruction cannot be discounted: the more a tutor knows about writing, the more resources she has to draw upon. However, expertise in teaching lies in understanding how to use that knowledge: choices are contingent upon the constellation of learner, tasks, and context. Novice learners do not just know less, they know differently, than experts (Lloyd 2006); for explanations and exercises to make sense, a teacher, even a teacher of one, must establish at least some rudimentary shared orientation with the students, helping them define the tasks and goals they are about to embark upon. 
Our MATESL program teaches (and models) 'good' teaching as responsive mediation. This principle shapes the tutoring internship by providing enough time for responsive versatility to develop. The 12 weekly meetings allow tutor and tutee to build a repository of shared references, meanings, and concepts that can serve as semiotic touchstones for more successful interaction. This change in perspective - from defining the primary task of tutoring as giving knowledge to understanding tutoring as responsive interaction - is apparent in these excerpts from tutors' final course papers:

when I was tutoring here as an ESL writing tutor, my role shifted from a knowledge conveyer to a 'facilitator'.

during the course and during the progress of tutoring, a lot of the ideas and concepts I had have been reshaped [...] As a person and as a teacher, I now have greater insights of how to view students, effectively teach student[s], and build relationships with students [...] I am not simply a teacher: I am a tutor, a listener, a friend, a facilitator, and I can be so much more.

I think as a tutor we are helpful not because we are 'expert writer', instead it may because we are 'experienced writer'. We have gone through some tough periods concerning English writing but the precious knowledge that we've gained from such experiences would become priceless treasure that we could share with our tutees.

\section{Self-directed Mediation through Reflection}

Typically, in teacher education, there is a tension for the novice in being a teacher and a student at the same time (Johnson and Golombek 2016). The student teacher must navigate content and pedagogy, reception and delivery. In the student role, the novice teacher tends to cede content knowledge to the more-expert teacher educator; as an instructor, however, the novice experiences first-hand the way pedagogy and content knowledge intertwine. It is always interesting to see this shift illustrated in the tutors' reflective writings. As they come to realize that there are actually two kinds of novices undergoing development (themselves and their tutees), they begin to step outside of, and evaluate, that tension and see it as a productive dynamic:

finally, in the process of helping my tutees, I myself have also learned lots of things about academic writing. Before this semester, I even didn't know what a 'thesis statement' was. While now I would say that I'm really familiar with different types of essays and how to compose them in a clear and powerful way. This experience makes me realize that teaching is not just about giving, but rather, it's also a process of learning.

in this program, I also learned something as a student. I had heard several times that some teachers would say 'I did not learn to write until I teach the [first-year writing class].' It was true. I learned to write with my tutees.

I felt excited that I was applying what I had learnt to practice.

They also begin to comment on the changes in their own cognition:

though I am not an expert yet, I feel encouraged by this experience to equip myself with more theoretical knowledge about teaching and writing.

I did not realize it was important to learn about one's literacy until I did it this semester. Now I know that it would influence the way of thinking, the way they organize their article, and even the way they interpret the topic. 
They are surprised to see that their own definition of tutoring changes: tutoring comes to be seen as a balancing act between technical knowledge and pedagogical skill:

I thought [explaining grammar in detail] could add more credibility into my tutoring. However, after being requested to explain the meaning of almost each and every term I had used, I suddenly realized how unprofessional I was to teach someone like this. Teaching is not about showing off how much you know that others do not know, but about using the simplest way to let the student understand and be able to put the knowledge they have acquired into use.

In my previous teaching experience, I could prepare lesson plans and activities which would be used in class. This time, however, lesson planning was not possible because I did not know what specific challenges the student experienced with his writing. This situation forced me to immerse myself in the lesson.

Like it or not, the tutors, from day one, experience - and begin to think about - the flexibility of orientation that will be required of them throughout the semester.

\section{Prolepsis: The Future in the Present}

Reflective narratives are not only products of experience, they are tools for 'acting with foresight' (Johnson and Golombek 2002: 4). Reflective writing serves to recount and explain the past, but it also allows the writer to participate in what Bridgeman (2005: 130) calls 'anticipated recall'to speak, if only momentarily, from a place of future consolidated expertise. For a very brief moment, in words if not fully in activity, the reflective writer creates a proleptic, or future, self.

The act of reflecting upon the past from the future is familiar to literary critics. As one scholar puts it, prolepsis contains (italics are mine) an 'elaborate power to conjoin the forward motion of narration to the backward motion of explanation and therefore to instruct the experience of events in relation to futures that have not yet occurred' (Currie 2009: 324). For teachers in training, the explicit question of a reflective piece is 'what have I learned from the past for future use?' The implicit one is 'How will I feel/act/think when that knowledge is so fully appropriated, that I can't remember not knowing it?'. SCT embraces prolepsis as an act of semiotic creativity, of stepping into the future, if only momentarily (John-Steiner and Mahn 1996). Proleptic action pushes development forward by letting the learner engage in activity that is still 'ahead' of one's actual level of development; by outperforming your competence, so to speak, you actually change it.

In our teacher education program, we seek to create many opportunities for prolepsis among the students. We want our novice instructors to take their future selves seriously. Of course, proleptic moments in tutor writing are just that: moments. They are flashes of future time, briefly exposed and not always fully understood as such. Linguistic signs of proleptic orientation can be syntactical (asking questions implies the future expertise to answer them) and lexical (modal verbs and other forward-focused cognitive verbs):

by reading her essay, I also find limitations of my own. My ignorance about the content she writes may hinder my understanding of the way she writes. I wonder if having shared knowledge with your tutee also contributes to the effectiveness of ESL tutoring.

then in what way can I help? What can I bring to this tutoring?

Sometimes the future is explicitly identified:

I was pleasantly surprised at the new experiences I had as well as the experiences I know I have yet to encounter. 
And sometimes the writer looks in both directions, placing herself firmly in the continuum of her own past, present, and future development:

also, I learned a lot from him as much as he had gotten help from me. I believe my tutoring experience with him would be a great asset to me as a teacher.

this program itself will become a good resource for my future teaching.

A benefit of externalizing a person's thinking about their own activity is that it opens up that activity for inspection (Singley and Boucher 1988). The tutoring internship is explicitly structured around the core SCT principle that learning happens best when new concepts are 'talked through' and reiterated in dialogue with others. Externalizing understanding makes it easier to evaluate (Verity 2006). Tutors typically recognize this principle first in terms of writing pedagogy itself and later realize that it applies to learning how to tutor as well:

The results [...] from our discussion made me realize just how important talking about one's writing can be for the writer. Then I realized that I hardly ever discuss my essays with anyone, and perhaps I should do so. [...] Overall, I felt that the discussion and planning was constructive and helpful, and I now understand how important this can be within the writing process.

I tried to [explain] that the point of a reflection was to invest some effort in thinking about a topic and relating it to one's self, rather than reach a pre-determined conclusion. In the process I realized that, having written so many reflections for MA-TESL course work, I have come to take the genre for granted. It was interesting to remember that back in my first semester, I also felt that anxiety: was I doing this right? What did my instructor want? In just two short years, I have realized that almost anything can be acceptable, because my effort or energy is what makes it so.

From an SCT perspective, discussion does not have to be public or directed to an outside listener. Although ostensibly written for an outside reader (the supervisor), tutor posts frequently resemble self-directed 'private speech' - a regulatory function of language production that is used to control activity (Verity 2006) - we talk to ourselves when we find a task difficult and need help in accomplishing it. Private speech, from a Vygotskyan perspective, is thought made visible - it is speaking-for-planning (examples include shopping lists, 'notes to self' and other everyday genres of text) for a future that has not yet arrived [...] until we create a symbolic version of it in writing (John-Steiner and Mahn 1996).

Here, for example, a tutor thinks aloud about thinking, noting the utility of intersubjectivity, of getting 'inside' the tutee's mind, of sharing the tutee's perspective:

tutoring is not just like my tutee has problem and I solve it, but more importantly, I begin to involve in it and then I have ideas and structure of the paper actually. I think my tutee gives me a chance to let me think what I would say if I were going to write the paper. Thanks to my tutee, I have chance to get involved and not just out of circle but I would be an insider and would begin to think like them.

In the next example, the tutor is working out how to 'think like a tutor,' that is, to balance knowledge and strategic instruction; in this excerpt, it is clear that the 'obviously' is directed at the writer herself, since there is no reason for her to think that it would be easy for the supervisor, her reader, to know this:

however, what I am still struggling with is how to explain something to Tutee $L$ without outright rewriting a sentence for her. Obviously it is very easy for me to look at one of her sentences and, in my mind, rewrite it so it is stronger in meaning. I try to ask questions that will lead her to say what I'm thinking but this isn't always easy.

In the first class meeting of the semester, the supervisor explains that tutoring is first about listening, second about reading, and only thirdly about making corrections. Typically, these 
comments make no sense to the interns. It is only some weeks later, having met and engaged with actual tutees, they are able to find meaning in the supervisor's words and appropriate that meaning for themselves:

When I reflect on my initial read-through of Tutee C's paper, I am pleasantly surprised to see a change in the way I approach my tutee's papers compared to the beginning of the semester.

This raises a pertinent question: Are the tutors simply 'ventriloquating' the beliefs of the supervisor, saying the words without completely understanding them? To some extent, yes. This is a typical stage in the journey towards expertise. The intersubjective creation and maintenance of shared meanings is fundamental to the design of the internship. The activity of tutoring is practiced and explored but not explicitly taught: 'what is meant and made known by what is said is always in part contingent upon what at that moment is tacitly taken for granted' (Josephs 1998: 196). The internship succeeds and development happens, despite an initially shallow understanding on the tutors' part of the theoretical concepts invoked, through 'words, symbols, and expressions [shared] with varying depths of intention and understanding' (Linell 2003: 219).

Success is seen in moments of emotional connection, crucial to cognitive transformation in the SCT perspective (Holodynski 2013). Affective language becomes an integral feature of reflection:

I'm excited about two major changes for both my tutees and myself. One is to help them become more 'conscious' writer with clear purpose and intention to write, and another is to develop myself as a writing tutor with reasoned rationale behind my tutoring practice.

this meeting with Tutee B excited me in that I finally came up with the clear idea of his problems in his writing 'style', which led me to rethink my writing. It was so exciting that you find the crucial point both in your and your tutee's writing, and then you could both work on it to improve.

In the course of several weeks and several thousand words, the novice tutors' definition of 'tutoring' has become more aligned with the expert definition supplied by their supervisor at the beginning of the internship. Importantly, the tutors realize that success is not a one-time event but a continuous process of activity, evaluation, and realignment:

I had no idea that the relationship between tutors and tutees could be so close.

This experience makes me realize that teaching is not just about giving, but rather, it's also a process of learning.

I no longer doubt my qualification as a 'non-native writing tutor' any more and started to recognize and value what l've got that could help me become a better teacher.

I felt deep inside me that I want to be a teacher like that, who can help her students to be a better writer.

now I will not respond to my tutees' questions randomly without considering the sequence, the relative importance and what works best for them. In addition, I [want to] help my tutees develop the strategies that they could use in other situations instead of directly telling them the answer so as to promote their development as an independent writer with clear purpose, principle, and consciousness.

The journey never really finishes. 


\section{Conclusion}

The most satisfying aspect of the internship experience is seeing the tutors 'come around' to a new, more-expert orientation towards the activity of tutoring. They display important insights into the nature of their own expertise. The future is not a distant and mostly imagined place but is now a proximal space, just within their semiotic grasp. It is a space within which they are ready to employ both their agency and their skills. Most of all, it is 'different' from now, but the differences lie along a path along which they have already taken their first steps. Now they are ready to begin:

I have painted myself a picture about what kind of tutor I desire to be. I said to myself I would like to be a tutor who can be trusted and relied on [...] I would like to be a tutor who can help her to make a difference [...] Thanks to Tutee $Y$ I have learned to be more open-minded and learn to appreciate the differences between people. I think this is especially important for me if I become a real ESL teacher in the future. The first thing I need to deal with is to understand that all the students in my class may be different from each other, and they are different from me.

The data and discussion presented in this paper have at least two important implications for tutor education. First, fundamental dialectical tensions must be recognized, nurtured and evaluated when assessing the progress that novice tutors make in their journey to expertise. Second, tutor education can benefit from the same opportunities for praxis - a constellation of practical activity, theoretical insights, and skilled mediation - that teacher education does.

One key point of tension and potential growth resides between existing knowledge and new knowledge. Even first-time tutors bring some kind of informal understanding of what it means to tutor to the internship. Tutor education programs need to provide novice tutors with an arena of activity that allows them to put that informal understanding into direct engagement with real tutees and real-world goals as a first step towards transforming it to principled expert knowledge.

A second tension exists between what the tutors encounter in their tutoring sessions and what they read and discuss in class. As Nordlof's insightful paper notes, there is a distinct lack of theoretical grounding for much of what we practice in tutoring and tutor training (Nordlof 2014). The data suggests, unsurprisingly from the point of view of SCT, that novice tutors find it useful and productive to learn about the theoretical roles of interaction and mediation, so that they can tentatively begin to apply theoretical insights to their own practical activity.

Finally, we need to recognize the way emotions interact with cognition, especially in novice activity. The tutors cited above clearly use their emotional reactions (and those of their tutees) to gauge success, despite the lack of emotion as a typical normative factor in academic writing instruction. Being novices, these tutors use affective clues to evaluate their own activity, to motivate themselves, and to find footholds in what can be a series of overwhelming tasks.

This discussion suggests that we should give the education of tutors a more established place within the field of teacher education. Novice tutors can benefit from the same principled set of reflective, cognitive and affective tools that inform our best teacher education and development programs.

Intensive and continuing reflective writing helps novice tutors gain expertise not just in the activity of tutoring, but also in their own understanding of what it means to transform and be transformed. Encouraging continuous, intensive and thoughtful reflection by novice tutors is a straightforward way to add another layer of mediation and discussion into any tutor training program.

*Note: The data used in this study was collected under the guidelines of the Institutional Review Board office of the university; volunteer participants were recruited from the internship class the first day of the semester. Data was used only from students who consented to participate. The 
researcher/instructor did not have access to the consent forms until after final course grades were assigned. 


\section{References}

Bridgeman, T. (2005) 'Thinking Ahead: A Cognitive Approach to Prolepsis'. Narrative 13 (2), 125-159

Currie, M. (2009) 'The Novel and the Moving Now'. Novel: A Forum on Fiction 42 (2), 318-325

Daniels, H. (2013) 'Dialectic and Dialogic: The Essence of a Vygotskian Pedagogy'. CulturalHistorical Psychology 3, 70-79

Golombek, P., and Johnson, K.E. (2004) 'Narrative Inquiry as a Mediational Space: Examining Emotional and Cognitive Dissonance in Second-Language Teachers' Development'. Teachers and Teaching: Theory and Practice 10 (3), 307-327

Holodynski, M. (2013) 'The Internalization Theory of Emotions: A Cultural Historical Approach to the Development of Emotions'. Mind, Culture, and Activity 20 (1), 4-38

Johnson, K.E., and Golombek, P.R. (2016) Mindful L2 Teacher Education. New York: Routledge

Johnson, K.E., and Golombek, P.R. (2002) Teachers' Narrative Inquiry as Professional Development. New York: Cambridge University Press

John-Steiner, V., and Mahn, H. (1996) 'Sociocultural Approaches to Learning and Development: A Vygotskian Framework'. Educational Psychologist 31, 191-206

Josephs, I.E. (1998). 'On Dialogue and Silence, Poetry and Pedantry, and Cleverness and Wisdom in Psychology (An Interview with Ragnar Rommetveit)'. Culture and Psychology 4 (2), 189-212

Lantolf, J.P., and Poehner, M.E. (2014) Sociocultural Theory and the Pedagogical Imperative in L2 Education. Vygotskian Praxis and the Research/Practice Divide. New York: Routledge

Lantolf, J.P., and Poehner, M.E. (eds.) (2008) Sociocultural Theory and the Teaching of Second Languages. London: Equinox Publishing Ltd

Linell, P. (2003) 'Dialogical Tensions: On Rommetveitian Themes of Minds, Meanings, Monologues, and Languages'. Mind, Culture, and Activity 10 (3), 219-229

Lloyd, G. (2006) 'Preservice Teachers' Stories of Mathematics Classrooms: Explorations of Practice Through Fictional Accounts'. Educational Studies in Mathematics 63, 57-87

Nordlof, J. (2014) 'Vygotsky, Scaffolding, and the Role of Theory in Writing Center Work'. The Writing Center Journal 34 (1), 45-64

Polkinghorne, D.E. (1988) Narrative Knowing and the Human Sciences. Albany: State University of New York Press

Sengupta, S., and Xiao, M.K. (2002) 'The Contextual Reshaping of Beliefs About L2 Writing: Three Teachers' Practical Process of Theory Construction'. TESL-EJ [online] 6 (1). available from <http://www.tesl-ej.org/ej21/a1.html> [3 October 2018]

Singley, C.J., and Boucher, H.W. (1988) 'Dialogue in Tutor Training: Creating the Essential Space for Learning'. The Writing Center Journal 8 (2), 11-22

Verity, D. (2006) 'How Professionals Think: Private Speech in Teaching'. in JALT2005 Conference Proceedings. ed. by Bradford-Watts, K., Ikeguchi, C. and Swanson, M. held 7-10 October 2005 at Shizuoka Granship. Tokyo: JALT. [online] available from <http://jalt-publications.org/archive/proceedings/2005/E027.pdf> [3 October 2018] 